\title{
Cardiac surgery and the coronavirus disease 2019 pandemic: What we know, what we do not know, and what we need to do
}

Faisal G. Bakaeen, MD, ${ }^{a}$ A. Marc Gillinov, MD, ${ }^{a}$ Eric E. Roselli, MD, ${ }^{a}$ Joanna Chikwe, MD, ${ }^{b}$ Marc R. Moon, MD, ${ }^{\mathrm{c}}$ David H. Adams, MD, ${ }^{\mathrm{d}}$ Joseph S. Coselli, MD, ${ }^{\mathrm{e}}$ Joseph A. Dearani, MD, ${ }^{\mathrm{f}}$ and Lars G. Svensson, MD, $\mathrm{PhD}^{\mathrm{a}}$

As it unfolds, the coronavirus 2019 (COVID-19) pandemic is proving to be the seminal challenge of our generation. The human and economic toll has been felt across the globe, with no proven effective treatment or vaccine on the horizon. ${ }^{1}$ To impede viral transmission, local authorities and governments around the world have imposed aggressive containment measures by quarantining initial COVID-19 clusters and in many cases instituting a complete nationwide lockdown.

Health care systems were hit by a tsunami of patients and their resources stretched to breaking points. Shortages of personal protective equipment (PPE), sanitation products, ventilators, and intensive care unit (ICU) beds have been widely reported. To preserve PPE and prepare for the potential surge of COVID-19 patients to US hospitals, the Centers for Medicare and Medicaid Services asked for deferral of nonessential procedures and surgeries. ${ }^{2}$ Professional societies and experts in various fields have put forward guidance recommendations regarding triaging patients and resource utilization during this crisis. ${ }^{3-5}$

Surgeons are natural leaders when it comes to responding to disasters during both peace and wartime. The founders of both Cleveland Clinic and Mayo Clinic were inspired to found their institutions by experiences and observations made during wartime collaboration in the delivery of emergency care. ${ }^{6}$ Michael DeBakey was tasked by the country's leadership to document the history of medicine and surgery of the army after World War II. This work led him to conceive of mobile army surgical hospital units as a solution to many of the problems encountered by Army medical care of soldiers during the war. It was an offshoot of what he did with Edward Churchill, who was at the time chief of surgery at

From the ${ }^{a}$ Department of Thoracic and Cardiovascular Surgery, Heart, Vascular, and Thoracic Institute, Cleveland Clinic, Cleveland, Ohio; ${ }^{\mathrm{b}}$ Department of Cardiac Surgery, Smidt Heart Institute, Cedars-Sinai Medical Center, Los Angeles, Calif; ${ }^{c}$ Division of Cardiothoracic Surgery, Washington University School of Medicine, Barnes-Jewish Hospital, St Louis, Mo; ${ }^{\mathrm{d}}$ Department of Cardiovascular Surgery, Icahn School of Medicine at Mount Sinai, New York, NY; ${ }^{\mathrm{e} D i v i s i o n}$ of Cardiothoracic Surgery, Baylor College of Medicine, Houston, Tex; and ${ }^{\mathrm{f} D e p a r t m e n t}$ of Cardiovascular Surgery, Mayo Clinic, Rochester, Minn.

Received for publication April 24, 2020; revisions received April 24, 2020; accepted for publication April 27, 2020; available ahead of print May 6, 2020.

Address for reprints: Faisal G. Bakaeen, MD, Department of Thoracic and Cardiovascular Surgery, Cleveland Clinic, 9500 Euclid Ave, Desk J4-1, Cleveland, OH 44195 (E-mail: bakaeef@ccf.org)

J Thorac Cardiovasc Surg 2020;160:722-6

$0022-5223 / \$ 36.00$

Copyright (c) 2020 by The American Association for Thoracic Surgery

https://doi.org/10.1016/j.jtcvs.2020.04.101

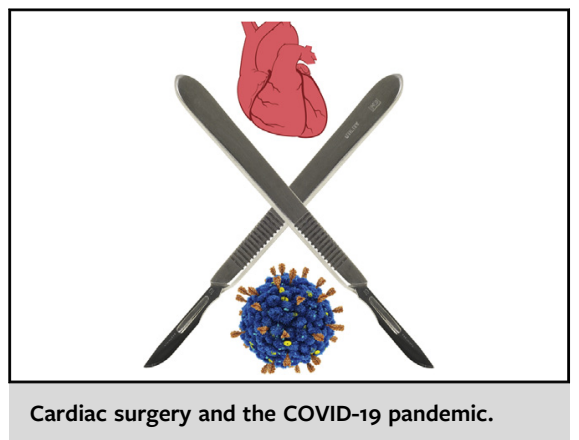

CENTRAL MESSAGE

The COVID-19 pandemic has influenced all aspects of our lives. Cardiac surgeons are faced with the challenge of caring for patients with life-threatening conditions in unprecedented circumstances.

See Commentaries on pages 727 and 728 .

Massachusetts General Hospital but had spent time as chief consultant to the North African and Mediterranean theaters. During the Korean War, mobile army surgical hospital units stationed doctors closer to the front lines and improved the survival of wounded soldiers; this became a model for modern-day civilian onsite disaster medical response. ${ }^{7}$ Cardiac surgeons have now been thrust to the frontlines in the fight against an elusive enemy: COVID-19.

Herein, we summarize key elements of the pandemic as it pertains to cardiac surgery. We start with what we know about the current state of affairs, then address uncertainties and gaps in our knowledge. We focus on what cardiac surgeons need to do to lead the preparation for the next phase of the pandemic and the eventual transition back to normalcy.

\section{WHAT WE KNOW}

Many COVID-19 manifestations will require cardiac surgical intervention. ${ }^{8}$ From instituting extracorporeal membrane oxygenation (ECMO) and other forms of mechanical circulatory support to managing infected 
immunosuppressed cardiothoracic transplant patients, cardiac surgical expertise is required. In addition, cardiac surgery programs possess infrastructures and resources that are in critical demand to care for many hospitalized COVID-19 patients. Therefore, by necessity, resources have been diverted away from cardiac surgery, and in many instances cardiac units have been repurposed as COVID-19 units, some of which are actually run by cardiac surgeons who leverage their critical care experience and leadership. ${ }^{9}$ In Italy's Lombardy region, 16 of 20 cardiac surgical units discontinued cardiac operations, with the remaining 4 units forming the hub for the 16 other closed units. ${ }^{10}$ In New York and many other US states, all nonemergency cardiac surgery was suspended early in response to the rising numbers in the population infected with COVID-19.

The role of ECMO in treating critically ill COVID-19 patients is evolving, but mortality is uniformly high and little is known about the long-term lung function of survivors. ${ }^{11,12}$ The Extracorporeal Life Support Organization recommends selective use of ECMO in COVID-19 patients and advises against starting new ECMO centers for the sole purpose of treating COVID-19. ${ }^{12}$ Recognizing the dismal outlook for patients with COVID-19 myocarditis and severe pulmonary involvement, many centers have elected not to institute ECMO in COVID-19 patients with these complications. Ethical considerations come into play not only in decision making about patient care and the role of ECMO, but also in day-today cardiac surgery practice during these uncharted times.

When caring for COVID-19 patients, it is important to remember the real risks associated with the viral infection. Health care workers are estimated to account for $19 \%$ of cases reported to the Centers for Disease Control and Prevention, and more than half reported contact with a COVID-19 patient only in a health care setting. ${ }^{13}$ Most health care workers with COVID-19 were not hospitalized; however, severe adverse outcomes, including 27 deaths (ie, $0.3 \%-0.6 \%$ of the health care workers who tested positive for COVID-19), have been reported. ${ }^{13}$ In addition, families of caregivers can also be at increased risk, with rates of household transmission of COVID-19 in China estimated at $16 \%$ to $30 \%,{ }^{14,15}$ and that is likely an underestimate of the actual risk. These findings underscore the importance of protecting the health of all caregivers. Such realities, coupled with other challenges and disruptions caused by the pandemic, create additional stress in what is already a high stakes field.

As the COVID-19 threat preoccupies the world, it is easy to overlook the long-standing, ongoing cardiovascular disease burden. According to a survey conducted in March 2020, among 60 centers from around the world participating in a randomized trial of multiarterial grafting in coronary artery bypass surgery, there was median reduction in cardiac surgery case volume of $50 \%$ to $75 \%$, a figure that correlated with the number of local COVID-19 cases. Most centers $(57 \%)$ restricted their cardiac surgery activity to urgent/emergency cases, and $5 \%$ canceled all cardiac surgery; $32 \%$ of the centers relocated cardiac surgical personnel to other care areas. The majority of the centers suspended or modified research activity. ${ }^{16}$

Deaths of patients with severe aortic stenosis awaiting valve replacement, with aortic aneurysms awaiting repair, or with coronary artery disease awaiting revascularization serve as powerful reminders that cardiac surgery is often not elective, and many patients have life-threatening cardiovascular conditions. ${ }^{17,18}$ To compound this problem, alarming data are emerging to suggest that patients are avoiding medical care during the COVID-19 pandemic to minimize potential exposure. One study estimated a $38 \%$ reduction in US cardiac catheterization laboratory ST-elevation myocardial infarction activations, similar to the $40 \%$ reduction observed in Spain. ${ }^{19}$ Access of care issues, ST-elevation myocardial infarction misdiagnosis, and increased use of pharmacological reperfusion due to COVID-19 are other possible but less likely explanations for this observation.

At the same time, at a busy center in Italy during the surge there was a remarkable example of successful continuation of thoracic oncologic care. There was a $22 \%$ reduction of case volume, but the outcomes were encouraging, with no patients converting to COVID-19 positive during follow-up and no postoperative readmissions related to COVID-19. This accomplishment was achieved with rigorous protocols. ${ }^{20}$ Nevertheless, data from Wuhan, China, showed that of 11 patients undergoing thoracic surgery who postoperatively were found to be COVID-19 positive, 3 (27\%) died. ${ }^{21}$

\section{WHAT WE DO NOT KNOW}

As cardiac surgeons ponder the next steps in dealing with the pandemic and its aftermath, they encounter the universal challenge of accurately predicting the future. Current COVID-19 models are fraught with limitations to account for multiple unknown factors, such as accuracy of diagnostic tests, waning of immunity, possible reinfection, and the possibility that important variables like degree of social distancing might change over time. ${ }^{22}$ Predictive models for large countries such as the United States become even more complex because of heterogeneous subepidemics in local areas. ${ }^{22}$

To date, we know little about the safety of performing cardiac surgery during the pandemic. Although it varies from center to center, risk of COVID-19 exposure and infection in hospital settings and the extent and influence of diversion of personnel and resources away from cardiac surgery is unknown. Cardiovascular intensivists from some of our units have almost uniformly been redeployed to care for COVID-19 patients, further challenging current team performance. A long-term decrease in surgical volume may blunt surgical skills and team effectiveness.

Operating on nonurgent patients during the height of the pandemic may be a high-risk proposition. In a study of 34 
patients who underwent noncardiac surgical procedures at hospitals in Wuhan, China, and then tested positive for COVID-19, 15 (44\%) needed ICU care, and mortality was $20.5 \% .^{23}$ All the patients developed pneumonia, and ICU admissions were more prevalent in patients undergoing complex procedures. As previously mentioned, mortality of $27 \%$ was reported in another study from a thoracic surgery unit in Wuhan. ${ }^{21}$ There were no cardiac surgery patients in these cohorts, but one can speculate that the prevalence of hypertension and other pre-existing comorbidities compounded by cardiopulmonary bypass and the need for mechanical ventilation might add to the physiologic insult and risk in such patients.

The risk of performing emergency cardiac surgery on known symptomatic COVID-19 positive patients is unknown, but mortality would be expected to be higher than under normal circumstances. We also do not know the safe time to operate on a patient who has recovered from the infection or whether there is a risk for COVID-19 reactivation.

Although the risk of exposure and infection in health care personnel is well documented,$^{13}$ the specific risk to cardiac surgeons is unknown. Obvious sources of exposure include aerosol from ventilators, respiratory treatments, chest tube air leaks, and electrocautery. Insufflation used in endoscopic saphenous vein harvesting also presents an aerosolization risk. Reoperations are particularly risky because of the potential for parenchymal lung injury during sternal re-entry and mediastinal dissection. For surgeons who get infected, when can they safely return to work? Should we wait until they test negative for the virus or is there a more robust parameter?

Some have speculated that the reluctance to be at hospitals during the pandemic and the resultant delay in care could create a pool of patients who will enter the hospital in more critical condition. For example, will there be a resurgence of mechanical myocardial infarction complications such as papillary muscle ruptures with acute mitral regurgitation, postinfarction ventricular septal defects, and freewall ruptures, or more patients presenting late with acute aortic syndromes? Of course, a bigger concern is that many of these patients will never get care at all and die at home from potentially treatable cardiovascular conditions. This concern is borne out, at least partly, in recent reports of deaths in the United States exceeding what is historically expected even after accounting for deaths attributable to COVID-19.

Another important issue is a surge in cardiac demand due to the backlog of canceled or postponed cases. Although some cardiac centers may dial up to prepandemic levels or beyond, other cardiac programs may not survive the disruptions and system attrition caused by the pandemic.

COVID-19 will cost the global economy several trillion dollars. ${ }^{24}$ The financial influence of the pandemic on health care systems is unclear at this point, but COVID-19 will be a financial stress test that reveals vulnerabilities. ${ }^{25}$ Moody's Investors Service, a bond credit-rating agency, downgraded its financial outlook for not-for-profit and public hospitals in the United States from stable to negative during midMarch 2020. ${ }^{25}$ Hospitals with strong operating cash-flow margins and sufficient cash on hand will fare better than those without it. The Coronavirus Aid, Relief, and Economic Security Act was recently passed by Congress, and additional recovery packages may be on the way, but this is a short-term fix and will become insufficient at the current level of funding. Sadly, layoffs, furloughs, and pay cuts are occurring, with the risk of eroding our response to the pandemic and lowering morale among cardiovascular health care workers.

Many other questions remain unanswered: How soon can states begin large-scale testing, rigorous contact tracing, and antibody testing? How useful is the latter and will it be a reliable indicator of immunity? What is the risk of reinfection? Once states begin to reopen for business, will there be a second wave of the pandemic, and will the surge be just as bad as or even worse than the initial outbreak? How long will it be before an effective treatment and vaccine become available? Will there be threats from new viral pandemics or other natural or manmade disasters? All patients undergoing cardiac surgery should have COVID-19 virus testing immediately before surgery, but how should we manage those with a positive test? Future investigations will provide some answers and additional clarity.

\section{WHAT WE NEED TO DO AND THE ROAD TO RECOVERY}

It is important to emphasize 3 key realities: First, this is a dynamic crisis; things are moving rapidly and not necessarily in a predictable direction. Second, different regions are affected to different extents and are at various time points along the course of the pandemic. As we write this document, most states have not reached the peak of the epidemiologic curve, and some may not experience a distinct peak. Third, the capacity and preparedness of health care systems will vary by location. Because of this variability, there is no 1size-fits-all list of recommendations about what cardiac surgeons need to do. It is difficult, if not impossible, to provide guideline documents, because evidence-based medicine related to this pandemic is not possible at the present time due to paucity of data. Consequently, many published manuscripts on COVID-19 to date have provided so-called guidance considerations. These guidance documents are largely determined by geographic area, local government recommendations, hospital protocols and resources, and personnel and staffing issues. It is also important to emphasize that these recommendations are continuously evolving and changing. With this information in mind, there are certain guiding principles that we will highlight and share.

Our core mission remains to care for our patients and provide the best possible cardiac care. Obviously, there are competing priorities. That said, decisions about delaying treatment should not be based on disease entities per se, 


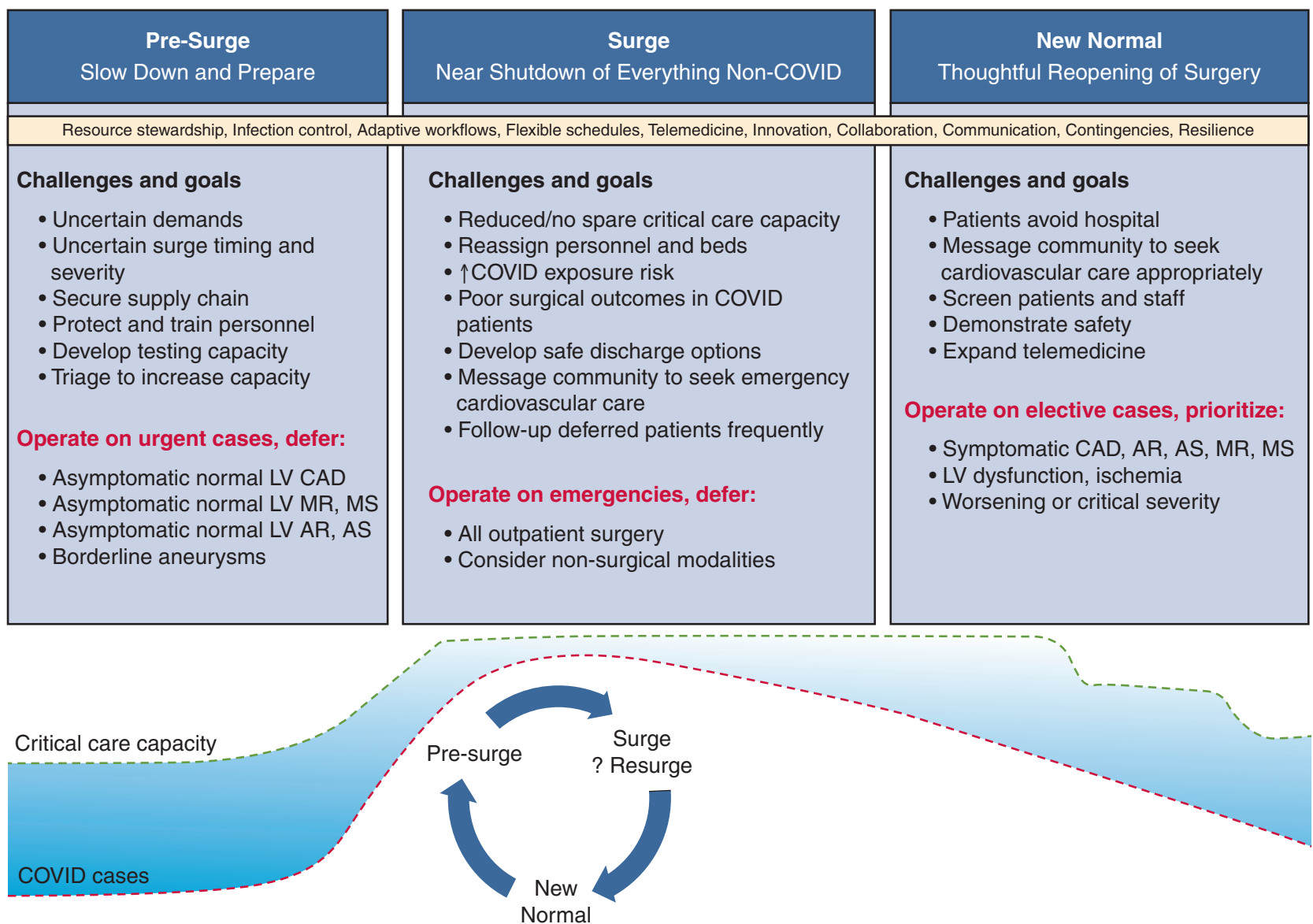

FIGURE 1. Challenges and goals of reopening cardiac surgery during the pandemic. $L V$, Left ventricular; $C A D$, coronary artery disease; $M R$, mitral regurgitation; $M S$, mitral stenosis; $A R$, aortic regurgitation; $A S$, aortic stenosis; $C O V I D$, coronavirus disease.

but rather on the severity of illness and chances of successful treatment. Resources should be allocated based on specific protocols and criteria, irrespective of whether the need is related to COVID-19 or an unrelated illness.

Triage and delays may be inevitable for now and at some locations more than others, but hopefully few patients with a potentially curable cardiac disease will suffer because of the COVID-19 season. This message may be misunderstood or misinterpreted unless cardiac surgeons and others in cardiovascular medicine unite and deliver it to decision makers and to the public. This can be done through education, advocacy, and outreach. But first, we must ensure and demonstrate safety.

To safely care for our patients, exposure to COVID-19 should be minimized and adequate resources should be in place. As states and hospitals ramp up their testing capabilities, particularly with rapid testing, all patients should be tested. COVID-19 positive cases will be delayed except for emergency situations, with surgery performed in dedicated operating rooms and recovery taking place in isolated units. Antibody testing can help with staffing assignments and with weighing risks for patients and caregivers. Safety protocols should be in place to ensure proper use of PPE and to handle possible exposures.
Another aspect of safety is ensuring good surgical outcomes despite the pandemic. It is important for cardiac programs to track their case volumes, case mix, risk of COVID19 infection, and outcomes in real time and share them with their team members, patients, and colleagues. This will dispel fears and instill confidence that will bring patients back for life-saving procedures. Poor outcomes related to suboptimal infection control or preventable surgical complications are not acceptable.

Patient and caregiver education and support are key elements to effectively fight the pandemic and achieve optimal recovery. Cardiac surgeons should be there to support their patients, their coworkers, each other, their families, and communities, and reciprocation will naturally follow. Technology will allow us to connect on a wider scale to spread and share accurate information instead of misinformation.

Going back to business as usual is a distant event at this point in time. Resource shortages are to be expected, with supply chain disruptions and resource diversion and reallocation. However, the decision regarding when and how to reopen or ratchet up cardiac surgery and interventional procedures should not be financially driven, but rather based on clear safety and capacity metrics (Figure 1). 
Ideally, one should strive to keep cardiac teams intact as we persevere through this storm. Plans should be put in place to bring back team members who were reassigned and to hire and train new members as needed. Smart and flexible scheduling will help facilitate maintenance of sharp skills while reducing potential exposure risk and allowing time for members to take care of themselves and their families. Telemedicine will likely transform the elective consultative practice in many centers, and adaptive workflows and optimized patient care pathways will save precious hospital resources.

Some programs may have to outsource their cardiac operations on a temporary or permanent basis. This is an important time to communicate and collaborate, share information and resources, and volunteer to help some programs recover. The same applies for educational and training programs. This pandemic can help us build valuable and enduring relationships for safe and effective patient care. The benefits of this collaboration will become more apparent when the pandemic is over.

As we rise to the challenge and face this crisis with hope and determination, we ponder how cardiac surgery might change. One thing that will definitely change is how we manage our resources, from simple face masks to more complex safety equipment. Good stewardship of not only material, but also human assets, will be a priority. Looking forward, nothing will be taken for granted, and contingencies will be part of any strategic planning. The qualities of leadership, resiliency, and innovation that are in the genetic blueprint of cardiac surgeons will enable us to prevail and ensure a secure and bright future for our specialty and for the well-being of our patients.

\section{Conflict of Interest Statement}

The authors reported no conflicts of interest.

The Journal policy requires editors and reviewers to disclose conflicts of interest and to decline handling or reviewing manuscripts for which they may have a conflict of interest. The editors and reviewers of this article have no conflicts of interest.

\section{References}

1. Barlow A, Landolf KM, Barlow B, Yeung SYA, Heavner JJ, Claassen CW, et al Review of emerging pharmacotherapy for the treatment of coronavirus disease 2019. Pharmacotherapy. April 7, 2020 [Epub ahead of print].

2. Centers for Medicare \& Medicaid Services. Non-emergent, elective medical services, and treatment recommendations. Available at: https://www.cms.gov/files/ document/31820-cms-adult-elective-surgery-and-procedures-recommendations.pdf. Accessed April 21, 2020.

3. Hassan A, Arora RC, Adams C, Bouchard D, Cook R, Gunning D, et al. Ramping up the delivery of cardiac surgery during the covid-19 pandemic: a guidance statement from the Canadian Society of Cardiac Surgeons. Can J Cardiol. April 29, 2020 [Epub ahead of print].

4. Stephens EH, Dearani JA, Guleserian KJ, Overman DM, Tweddell JS, Backer CL, et al. COVID-19: crisis management in congenital heart surgery. Ann Thorac Surg. April 11, 2020 [Epub ahead of print].

5. Haft JW, Atluri P, Alawadi G, Engelman D, Grant MC, Hassan A, et al; Society of Thoracic Surgeons COVID-19 Taskforce and the Workforce for Adult Cardiac and Vascular Surgery. Adult cardiac surgery during the COVID-19 pandemic: a tiered patient triage guidance statement. Ann Thorac Surg. April 10, 2020 [Epub ahead of print].

6. Clough JD, Studer PG, Szilagyi S, eds. To Act as a Unit: the Story of Cleveland Clinic. 5th ed. Cleveland, OH: Cleveland Clinic Press; 2011.

7. Altman LK. Michael DeBakey, rebuilder of hearts, dies at 99. New York Times. July 13, 2008. Available at: https://www.nytimes.com/2008/07/13/health/ 13debakey.html. Accessed May 5, 2020.

8. Fried JA, Ramasubbu K, Bhatt R, Topkara VK, Clerkin KJ, Horn E, et al. The variety of cardiovascular presentations of COVID-19. Circulation. April 3, 2020 [Epub ahead of print].

9. Harris S, Stead Sellers F. Inside a major New York City hospital system battling coronavirus. Washington Post. March 28, 2020. Available at: https://www. washingtonpost.com/national/inside-a-new-york-city-hospital-system-battlingcoronavirus/2020/03/28/38561d22-7071-11ea-a3ec-70d7479d83f0_story.html. Accessed April 21, 2020.

10. Bonalumi G, di Mauro M, Garatti A, Barili F, Gerosa G, Parolari A, et al; Italian Society for Cardiac Surgery Task Force on COVID-19 Pandemic. The COVID-19 outbreak and its impact on hospitals in Italy: the model of cardiac surgery. Eur J Cardiothorac Surg. April 17, 2020 [Epub ahead of print].

11. Zeng Y, Cai Z, Xianyu Y, Yang BX, Song T, Yan Q. Prognosis when using extracorporeal membrane oxygenation (ECMO) for critically ill COVID-19 patients in China: a retrospective case series. Crit Care. 2020;24:148.

12. Bartlett RH, Ogino MT, Brodie D, McMullan DM, Lorusso R, MacLaren G, et al. Initial ELSO guidance document: ECMO for COVID-19 patients with severe cardiopulmonary failure. ASAIO J. 2020;66:472-4.

13. Centers for Disease Control and Prevention COVID-19 Response Team. Characteristics of health care personnel with COVID-19-United States, February 12April 9, 2020. Available at: https://www-cdc-gov.ccmain.ohionet.org/mmwr/ volumes/69/wr/pdfs/mm6915e6-H.pdf. Accessed April 21, 2020.

14. Li W, Zhang B, Lu J, Liu S, Chang Z, Cao P, et al. The characteristics of household transmission of COVID-19. Clin Infect Dis. April 17, 2020 [Epub ahead of print].

15. Wang Z, Ma W, Zheng X, Wu G, Zhang R. Household transmission of SARSCoV-2. J Infect. April 10, 2020 [Epub ahead of print].

16. Chikwe J, Gaudino M, Hameed I, Robinson NB, Bakaeen FG, Menicanti L, et al. Committee recommendations for resuming cardiac surgery activity in the SARSCoV-2 era: guidance from an international cardiac surgery consortium. Ann Thorac Surg. May 15, 2020 [Epub ahead of print].

17. Malaisrie SC, McDonald E, Kruse J, Li Z, McGee EC Jr, Abicht TO, et al. Mortality while waiting for aortic valve replacement. Ann Thorac Surg. 2014;98: 1564-70.

18. Head SJ, da Costa BR, Beumer B, Stefanini GG, Alfonso F, Clemmensen PM, et al. Adverse events while awaiting myocardial revascularization: a systematic review and meta-analysis. Eur J Cardiothorac Surg. 2017;52:206-17.

19. Garcia S, Albaghdadi MS, Meraj PM, Schmidt C, Garberich R, Jaffer FA, et al. Reduction in ST-segment elevation cardiac catheterization laboratory activations in the United States during COVID-19 pandemic. J Am Coll Cardiol. April 9, 2020 [Epub ahead of print].

20. Maurizi G, Rendina EA. A high-volume thoracic surgery division into the storm of the COVID-19 pandemic. Ann Thorac Surg. April 11, 2020 [Epub ahead of print].

21. Peng S, Huang L, Zhao B, Zhou S, Braithwaite I, Zhang N, et al. Clinical course of coronavirus disease 2019 in 11 patients after thoracic surgery and challenges in diagnosis. J Thorac Cardiovasc Surg. April 10, 2020 [Epub ahead of print].

22. Jewell NP, Lewnard JA, Jewell BL. Predictive mathematical models of the COVID-19 pandemic: underlying principles and value of projections. JAMA. April 16, 2020 [Epub ahead of print].

23. Lei S, Jiang F, Su W, Chen C, Chen J, Mei W, et al. Clinical characteristics and outcomes of patients undergoing surgeries during the incubation period of COVID-19 infection. EClinicalMedicine. April 5, 2020;100331.

24. Orlik T, Rush J, Cousin M, Hong J. Coronavirus could cost the global economy \$2.7 trillion. Here's how. Bloomberg. March 6, 2020. Available at: https://www. bloomberg.com/graphics/2020-coronavirus-pandemic-global-economic-risk/. Accessed April 21, 2020.

25. Colenda CC, Applegate WB, Reifler BV, Blazer DG II. COVID-19: financial stress test for academic medical centers. Acad Med. April 13, 2020 [Epub ahead of print]. 